\title{
Simulation Based Skills Training in Neurosurgery and Contemporary Surgical Practices
}

\author{
Ashish Suri, Manjul Tripathi, Martin Bettag, Tara Sankar Roy, Sanjeev Lalwani \\ Neurosurgery Education and Training School, Department of Neurosurgery, \\ All India Institute of Medical Sciences, New Delhi, India
}

\begin{abstract}
SUMMARY
Neurosurgery training is based on a time-bound apprenticeship model, resulting in mentor-dependent, non-uniform, anecdotal, slow skills acquisition, sometimes with morbid consequences. The complexity of neurosurgical procedures and constraints of present education have demands for alternative methods of training. The use of simulation in surgical skills training was pioneered by work in laparoscopy, which began only in the last 25 years. Existing neurosurgery training model should be supplemented with efficient skills training curricula.

The present study illustrates formulation, standardization, validation and evaluation of efficacy of neurosurgery skills training modules using formative and summative assessment. 160 regular residents and short-term trainees were trained over 3096 skills training sessions under formative assessment; 176 'graduate neurosurgeons' were trained with 12 skills training programs under summative assessment. Training involved skills development in micro-neurosurgery, high-speed drilling, neuroendoscopy and spine-instrumentation by practice on structured low and high-fidelity simulation models. The effectiveness of content, course modules, and teaching faculty on skills development were assessed using spot and gap-based evaluation.
\end{abstract}

Seven basic, 7 intermediate and 14 advanced skills training modules have been developed. Trainees rated $71 \%$ of overall training sessions as excellent quality content with $69 \cdot 8 \%, 70 \cdot 1 \%$, and $71 \%$ respectively for micro-suturing and high-speed drilling, neuro-endoscopy and spine-instrumentation modules. Faculty with higher ratings was included as program instructors. On gap-based evaluation, $>80 \%$ of responded trainees

Correspondence : Prof. Ashish Suri, FAMS, Professor, Department of Neurosurgery, All-India Institute of Medical Sciences, New Delhi, India. Email: surineuro@gmail.com. Phone: +91-11-26593538; +91-9811479034; +919868398240. Fax:+91-11-26588559.

GOLDEN JUBILEE COMMEMORATION AWARD LECTURE delivered during NAMSCON 2015 at the All-India Institute of Medical Sciences, Patna. 
reported better orientation with high speed drilling followed by micro-neurosurgery and spine-instrumentation. Neuro-endoscopy training scored low assimilation into clinical practice.

We suggest structured modular validated skills training curriculum to supplement the existing neurosurgery training. This would help in improving learning curve outside operation-rooms, at convenience and individualized needs of trainees under supervision, and would thus help in skills translation without endangering patients.

Keywords : Competency, Curriculum, Modular, Neurosurgery Education, Residency, Simulation.

\section{INTRODUCTION}

Traditional residency training program has used the operation theatres to transfer the art and craft of surgery to residents. Till the end of last century, Halstedian training program had hardly any criticism; but in view of accelerating changes in health care system worldwide, apprenticeship model of training is being considered suboptimal (1). In this era of minimally invasive and robotic surgery, several forces are making it difficult for the operation theatres to be the predominant venue for the acquisition of primary technical skills (2). The reasons are manifold, as increasing financial and medicolegal constraints in the operating room are putting tremendous pressure on the residents and training faculty. Secondly, demand of maximum possible efficiency in surgical care because of patients being admitted with serious and complex surgical problems in the teaching institutes. There are several social and legal concerns about teaching basic skills on an already compromised human being. Last but not the least, is the increasing number of residents in surgical discipline and decreased work-hours leading to less and less opportunity to teach and supervise (3). All these problems are not exclusive to surgical discipline only but definitely surgery is the worst sufferer.

There is an ancient proverb, "The axe forgets, but the tree remembers". This concern becomes magnified in high-end branches like neurosurgery, as brain tissue is a non-forgiving structure. Intracranial structures have reluctance to minimal retraction forget about excision. As surgeons, our motto always remains, "First do no harm", but simultaneously we have a duty to pass on the expertise to the future generation. It is difficult to achieve this fine line of balance. Hence, there is a pressing need to develop methods of technical skills instructions that occur outside the operating rooms (4-8). The use of sporadic courses and workshops to teach basic skills is not a new concept. 
But, surgical skill acquisition is an on going practice, which is learnt over a course of time under a watchful eye. The need of the hour is to incorporate simulation based training curriculum to supplement regular training program in surgery. This will help in the initial learning curve of a naïve resident with safety to our patients (9-11).

Neurosurgery Education and Training School (NETS) is an attempt to establish a skills training curriculum from neurosurgical perspective to fill learning gap. It involved formulation, standardization, validation and evaluation of efficacy of structured modular skills training program for short-term and longterm training using formative and summative assessment tools (12-18).

\section{Methods :}

\section{Development of Neurosurgery Education and Training School}

\section{Infrastructure:}

Simulation in neurosurgery in India has made a significant step in education and skills training of neurosurgery on an academic and translational platform. NETS was established in 2009 at All India Institute of Medical Sciences (AIIMS), New Delhi, India with intra-institutional collaboration between departments of Neurosurgery, Anatomy, Forensic Medicine; interinstitutional collaboration with Indian Institute of Technology Delhi (IIT-D) and international collaboration with

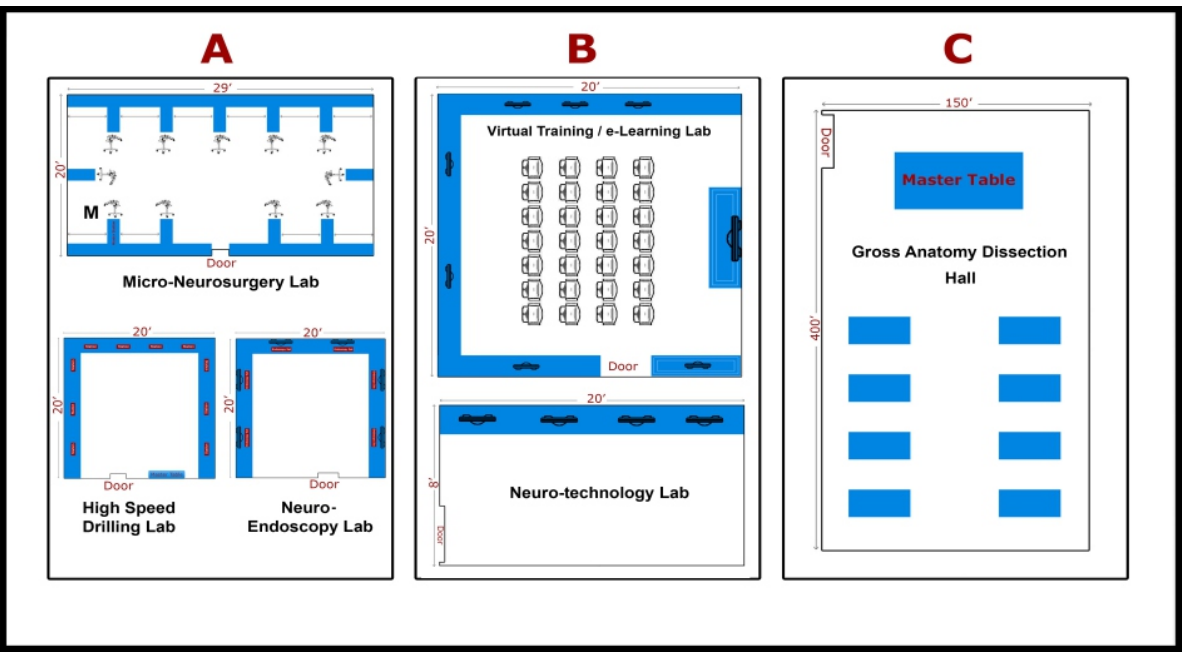

Fig. 1: Infrastructure of Neurosurgery Education and Training School (NETS). A. Micro-neurosurgery Skills Training Laboratory, High Speed Drilling Skills Training Laboratory and Neuro-Endoscopy Skills Training Laboratory;

B. Virtual Training e-Learning Laboratory and Neuro-Technology Laboratory; C. Gross Anatomy Dissection Hall for cadaver dissection. 
department of Neurosurgery, Hospital Barmherzige Bruder, Trier and department of Anatomy, University of Mainz, Germany. The facility consists of well-equipped separate skills training laboratories (Fig. 1) $(14,15)$.

Assessing the educational needs, NETS has also established an open source, free access, global, interactive elearning platform delivering customized educational content. The learning material includes neurosurgery seminars, modular courses, edited operation videos and 3D animation graphics content $(14,15)$.

At present, majority of neurosurgical procedures are performed under magnification. Under microscope, instruments move faster, field is several times magnified and tremors are more apparent (16). Transition from microscopic to neuro-endoscopy habitat is further challenging as one operates at a distance looking at a monitor with only 2 dimensions of vision and limited field of surgery. A neurosurgeon has to be more cautious and familiar not only with the changed view of the anatomy but also the changed habitat and their instruments (16).

Simulation helps in adapting the changed ergonomics of conventional microsurgery and neuro-endoscopy ORs. Neurosurgery Skills Training Facility comprise of well-established separate laboratories for micro neurosurgery, high speed drilling, neuro-endoscopy and gross cadaver anatomy laboratories. All laboratories are equipped with operating microscopes, endoscopes, microscopic and endoscopic instrument sets, pneumatic and electric drills, high definition cameras and monitors with recording and storage facilities. NETS comprise computer based and noncomputer based simulation for neurosurgery education and skills training $(14,15)$.

\section{Teaching Faculty at NETS :}

NETS follows strict trainee and teaching faculty inclusion criteria formulated by 'Scientific Advisory Committee' (NETS-SAC) consisting of experienced neurosurgeons.

\section{Selection criteria for trainees :}

Trainees are categorized as regular trainees, short-term trainees, workshop trainees and senior research fellows (1219).

- 'Regular-trainees' are postgraduate residents of institute designated "Senior Resident (SR)", (1-6 as per training year of residency). This corresponds to PGY system of American Medical Schools.

- 'Short-term trainees' are residents or practicing neurosurgeons from all over India and abroad. They are trained for 2-4 weeks.

- Trainees in three days 'Neurosurgery Skills Training Workshops' are certified practicing neurosurgeons. This workshop is organized quarterly, at 35 USD enrolment cost only.

- Certified post-doctorate senior 
research fellows/officers (SRO) are selected by the Indian Council of Medical Research (ICMR) for research on skills training and cadaver dissection.

\section{Selection Criteria for Teaching Faculty:}

The faculty should have keen interest and active involvement in practicing and teaching skill sets in neurosurgery for continuation as 'Curriculum Instructors' (CI). Trainees' feedback is taken into account to select faculty of maximum impact and identify faculty with CI potential.

\section{Teacher of Teachers (TOT) :}

TOTs are senior faculty members with more than 10 years experience of imparting skills training and evaluating other faculty members in the institutes. This helps in faculty up-gradation, with identification of potential faculty for skills training program.

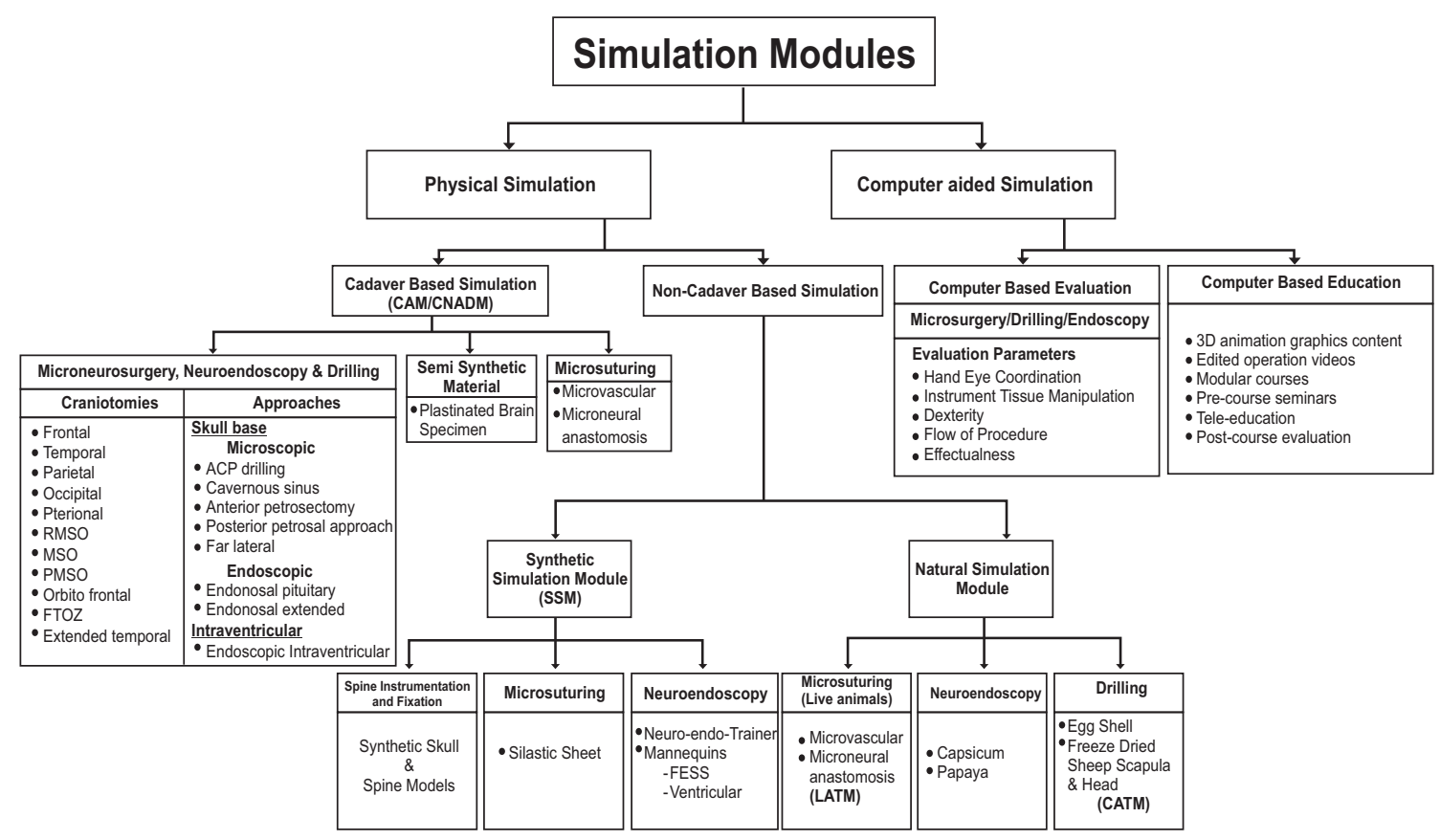

Fig. 2: Structured Simulation-based Skills Training Modules in Neurosurgery (ACP, Anterior Clinoid Process; CAM, Cadaver Anatomy Module; CATM, Cadaver Animal Tissue Module; CNADM,

Cadaver Neuroanatomy Dissection Module; FESS, Functional Endoscopic Sinus Surgery; FTOZ, Fronto-Temporal-Orbito-Zygomatic; LATM, Live Animal Tissue Module; MSO, Midline Suboccipital; PMSO, Paramedian Suboccipital; RMSO, Retromastoid Suboccipital; SSM, Synthetic Simulation Module; VDM, Video Demo Module) 
Table 1: Structured neurosurgery skills training modules for basic, intermediate and advanced stages of learning (CAM, Cadaver Anatomy Module; CATM, Cadaver Animal Tissue Module; CNADM, Cadaver Neuroanatomy Dissection Module; DNB, Diplomate of National Board; LATM, Live Animal Tissue Module; MCh, Magister Chirurgiae; SR, Senior Resident; SSM, Synthetic Simulation Module; VDM, Video Demo Module).

\begin{tabular}{|c|c|c|c|}
\hline Skills & Basic & Intermediate & Advanced \\
\hline Level & $\begin{array}{l}\text { SR1 (3 Year MCh/DNB) } \\
\text { SR3 (6 Year MCh/DNB) }\end{array}$ & $\begin{array}{l}\text { SR2 (3 Year } \mathrm{MCh} / \mathrm{DNB}) \\
\text { SR4 (6 Year MCh/DNB) }\end{array}$ & $\begin{array}{l}\mathrm{SR} 3 \text { (3 Year } \mathrm{MCh} / \mathrm{DNB}) \\
\mathrm{SR} 5,6(6 \text { Year } \mathrm{MCh} / \mathrm{DNB})\end{array}$ \\
\hline \multirow[t]{2}{*}{ Micro-Neurosurgery Modules } & $\begin{array}{l}\text { Suturing on Synthetic models } \\
(4-0 \text { to } 7-0)\end{array}$ & $\begin{array}{l}\text { Suturing on Synthetic models } \\
(9-0 \text { to } 10-0) \\
\text { Cadaver vessel and nerve anastomosis }\end{array}$ & $\begin{array}{l}\text { Sciatic Nerve Anastomosis } \\
\text { Femoral Vessel Anastomosis } \\
\text { (Live animal- rats/ guinea pigs) }\end{array}$ \\
\hline & VDM, SSM & VDM, SSM, CATM & VDM, LATM \\
\hline \multirow[t]{2}{*}{ High Speed Drilling Modules } & $\begin{array}{l}\text { Flap Design, Burr Holes, } \\
\text { Sheep Scapula drilling } \\
\text { Sheep head drilling }\end{array}$ & $\begin{array}{l}\text { Sheep head split calvarial graft, } \\
\text { Egg shell drilling, } \\
\text { Microscopic drilling(Sheep head/ Sheep } \\
\text { scapula) }\end{array}$ & $\begin{array}{l}\text { Microscopic cadaver drilling } \\
\text { Anterior clinoid process, } \\
\text { Petrous, } \\
\text { Far lateral } \\
\text { Endoscopic cadaver drilling } \\
\text { Endo-nasal extended skull base }\end{array}$ \\
\hline & VDM, CATM & VDM, CATM & CAM, VDM, CNADM \\
\hline \multirow[t]{2}{*}{ Neuro-Endoscopy Modules } & $\begin{array}{l}\text { Parts assembly, } \\
\text { Hand eye coordination practice on } \\
\text { capsicum, papaya (natural simulation) }\end{array}$ & Neuro-Endo-trainer & $\begin{array}{l}\text { Ventricular and Skull base anatomy, } \\
\text { ETV (Synthetic model) } \\
\text { FESS model, } \\
\text { Endo-nasal extended skull base (cadaver) } \\
\text { Endoscopic spine (optional) }\end{array}$ \\
\hline & VDM, NSM & VDM, SSM & CAM, VDM, CNADM \\
\hline \multirow[t]{2}{*}{$\begin{array}{l}\text { Spinal Instrumentation } \\
\text { Modules }\end{array}$} & $\begin{array}{l}\text { Entry points } \\
\text { Laminoplasty }\end{array}$ & $\begin{array}{l}\text { Anterior cervical plate fixation } \\
\text { (Synthetic model) }\end{array}$ & $\begin{array}{l}\text { Occipito-cervical fixation, } \\
\text { Odontoid screw placement, } \\
\text { C1-2 Trans-articular screw fixation, } \\
\text { Dorsal/ Lumbar pedicle screw fixation, } \\
\text { Inter-body Fusion }\end{array}$ \\
\hline & VDM, SSM & VDM, SSM & VDM, SSM \\
\hline
\end{tabular}

Neurosurgery Skills Training Modules (Table 1, Fig. 2) :

Skills training modules consists of structured modular approaches for neuroanatomy, micro-neurosurgery, neuroendoscopy, high-speed drilling and spine instrumentation. Modules are categorized into task-based (TBSM) and procedurebased sub-modules (PBSM) for the purpose of standardization and validation. TBSM are designed as skills training experiments, where the trainees' activities could be evaluated with the help of formative assessment. These modules are competency based and every person is upgraded for higher-level only if found competent at earlier skills level $(14,15)$.
Standardization of TBSM (Fig. 3) :

\section{Micro-Neurosurgery Skills Training Module :}

Micro-neurosurgery is practiced over sialistic sheet (marked in equal spaced squares of $\left.1 \times 1 \mathrm{~cm}^{2}\right)$, under predefined fixed criteria of suturing material and magnification.

\section{High Speed Drilling Skills Training Module:}

High speed drilling is practiced under magnification on defined criteria over an area marked with stencil. Trainee is asked to fashion all four-burr holes 

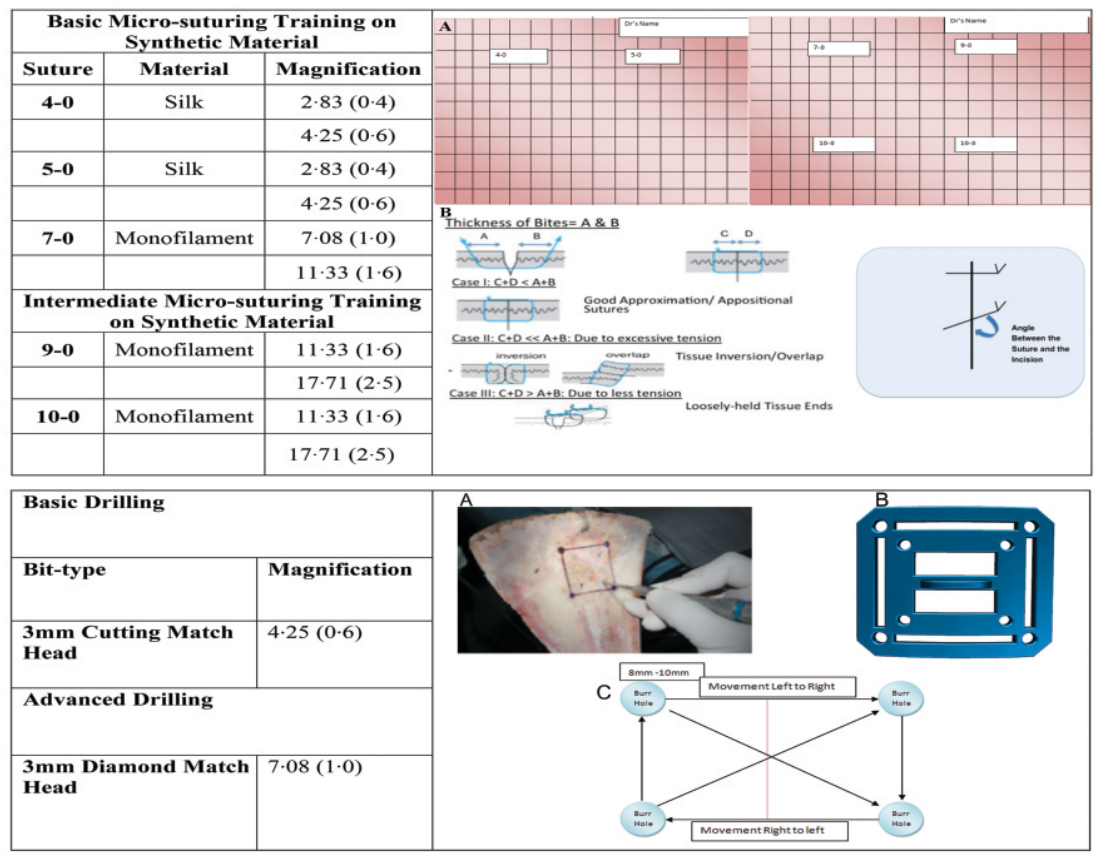

\begin{tabular}{|l|l|l|}
\hline Basic Neuro-endoscopy \\
\hline Particulars & Dimension \\
\hline Forceps & $160 \mathrm{~mm}$ \\
\hline Plate & Straight \\
\hline Collars & $20 \mathrm{~mm}$ \\
\hline Angle of scope & 0 degree \\
\hline Advanced Neuro-endoscopy & Dimension \\
\hline Particulars & $160 \mathrm{~mm}$ \\
\hline Forceps & Tilted (Left and Right) \\
\hline Plate & $10 \mathrm{~mm}$ \\
\hline Collars & $30 \mathrm{degrees}, 45$ degrees \\
\hline Angle of scope
\end{tabular}

Fig.: 3 Standardization of Micro-suturing Skills Training Module A, Synthetic material for micro-suturing training; B, Evaluation of effectualness of micro-suturing Standardization of High Speed Drilling Skills Training Module

A, Drilling practice on sheep scapula on standardized markers for evaluation;

$B$, The stencil for marking on sheep scapula/ head;

C The drilling practice patterns on stencil marked area.

Standardization of Neuro-endoscopy Skills Training module.

A, NETS Neuro Endo Trainer showing black and green pegs with rings at its base, a burr hole sized hole at the anterior aspect of the box for endoscope and instrument, and auxiliary camera for independent observation; $B$ and $C$, the acrylic base can be rotated in various directions for testing eye-hand co-ordinationperceptual switch; D, a trainee practicing on Endo-trainer with task based mechanism and viewing over the screen; E,F, pick and place with different angled 0, 30, 45 degrees endoscopes; $G, H$ patterns for doing the experiment 
Table 2: NETS criteria for neurosurgery skills evaluation. (NETS, Neurosurgery Education and Training School)

\begin{tabular}{|c|c|c|c|c|c|c|c|c|}
\hline $\begin{array}{c}\text { S } \\
\text { No. }\end{array}$ & Criteria & \multicolumn{2}{|c|}{ Evaluation Parameter } & 1 & \multicolumn{2}{|l|}{2} & 3 & 4 \\
\hline 1 & $\begin{array}{l}\text { Eye hand } \\
\text { coordination }\end{array}$ & \multicolumn{2}{|c|}{$\begin{array}{l}\text {-Handling of instruments } \\
\text { (Needle holder, forceps, drill, endoscope, } \\
\text { grasper) } \\
\text {-Depth perception (under magnification) }\end{array}$} & $\begin{array}{l}\text { Continuous } \\
\text { struggle } \\
\text { throughout the } \\
\text { activity }\end{array}$ & \multicolumn{2}{|c|}{$\begin{array}{l}\text { Frequent loss of } \\
\text { coordination }\end{array}$} & $\begin{array}{l}\text { Grossly smooth } \\
\text { coordination }\end{array}$ & $\begin{array}{l}\text { Perfect } \\
\text { coordination }\end{array}$ \\
\hline 2 & $\begin{array}{l}\text { Instrument } \\
\text { tissue } \\
\text { manipulation }\end{array}$ & \multicolumn{2}{|c|}{$\begin{array}{l}\text {-Tissue handling under magnification with } \\
\text { various instruments } \\
\text {-Appropriate pressure and force } \\
\text {-Confrontation with neighboring objects } \\
\text { (Repeated puncture) }\end{array}$} & $\begin{array}{l}\text { Grossly } \\
\text { unacceptable }\end{array}$ & \multicolumn{2}{|l|}{$\begin{array}{l}\text { Frequent } \\
\text { difficulty }\end{array}$} & Smooth handling & $\begin{array}{l}\text { Perfect } \\
\text { manipulation }\end{array}$ \\
\hline 3 & Dexterity & \multicolumn{2}{|c|}{$\begin{array}{l}\text {-Tremors/ jitteriness } \\
\text {-Therblig (intraoperative elemental motion) }\end{array}$} & $\begin{array}{l}\text { Irregular therblig/ } \\
\text { tremors/ jitteriness } \\
\text { throughout the } \\
\text { activity }\end{array}$ & \multicolumn{2}{|l|}{$\begin{array}{l}\text { Frequent } \\
\text { difficulty }\end{array}$} & Grossly smooth & Perfect dexterity \\
\hline 4 & $\begin{array}{l}\text { Flow of } \\
\text { procedure }\end{array}$ & \multicolumn{2}{|c|}{$\begin{array}{l}\text {-Time management during activity } \\
\text {-Total duration in task completion } \\
\text {-Unnecessary delays in inter or intra therblig }\end{array}$} & $\begin{array}{l}\text { Grossly } \\
\text { unacceptable }\end{array}$ & \multicolumn{2}{|c|}{ Frequent lapses } & Grossly smooth & Perfect flow \\
\hline 5 & Effectualness & $\begin{array}{l}\text { Evaluation of end result } \\
\text { for } \\
\text {-Micro-suturing or } \\
\text {-High speed drilling or } \\
\text {-Neuro-endosocpy }\end{array}$ & redefined criteria ${ }^{*}$ & $\begin{array}{l}\text { Grossly } \\
\text { unacceptable }\end{array}$ & \multicolumn{2}{|l|}{$\begin{array}{l}\text { Partially } \\
\text { acceptable }\end{array}$} & $\begin{array}{l}\text { Grossly } \\
\text { acceptable }\end{array}$ & Perfect end result \\
\hline \multicolumn{3}{|c|}{$\begin{array}{l}\text { Criteria for effectualness } \\
\text { A. } \text { Micro-suturing: } \\
\text {-Margins (Overlapped/ loose/apposed); } \\
\text {-Inter-sutural distance (equal/ unequal); } \\
\text {-Sutural distance on both sides of the incision } \\
\text { (equal/unequal); } \\
\text {-Angulation between suture and knot (Near } \\
\text { perpendicular- Yes/No) }\end{array}$} & \multicolumn{3}{|c|}{$\begin{array}{l}\text { B. High Speed Drilling: } \\
\text {-Drilled burr hole (cylindrical versus irregular } \\
\text { shape viz. cone, serpiginous) } \\
\text {-Intactness of dura/ inner core of egg/ periosteum } \\
\text { on other side of bone } \\
\text {-Drilling within stencil marked area } \\
\text {-Approximation of straight movement/ direction }\end{array}$} & $\begin{array}{r}\text { C. Ne } \\
\text {-Final } \\
1 . \\
2 . \\
3 . \\
4 .\end{array}$ & $\begin{array}{l}\text { roendoscopy: } \\
\text { osition of rings } \\
\geq 3 \text { rings slipped } \\
2 \text { rings slipped } \\
1 \text { ring slipped } \\
\text { All rings in place }\end{array}$ & \\
\hline
\end{tabular}

followed by drilling along the path in predefined direction.

\section{Neuro-endoscopy Skills Training module :}

Neuroendoscopy skills training module is practiced on NETS Neuro Endo Trainer box for pick and place experiment.

\section{Formative Assessment and Evaluation Parameters for Trainees :}

All skills training activities are recorded for self and expert evaluation. These sessions help in the development of eye-hand coordination, instrument-tissue manipulation, dexterity, speed and effectualness translating into steep learning curve. Each student is evaluated on structured spot four-point NETS criteria for basic neurosurgical skills (Table 2).

\section{Validation of Neurosurgery Skills Training Curriculum :}

'Neurosurgery Skills Training Workshops' are organized thrice a year for three days. On an average, 13-18 trainees are enrolled. Each training module consists of an interactive cognitive training regarding a procedure, video demonstration followed by recapitulation of techniques for use of instruments, followed by hands-on practice. Practice sessions comprise micro-neurosurgery, neuro-endoscopy, high-speed drilling and 
spine instrumentation. Teachers independently evaluate trainees on subjective and objective criteria. Such evaluation reduces the chances of observer bias. The best performers in each activity are awarded.

Summative assessment Criteria for Neurosurgery Skills Training Modules and Faculty Evaluation :

Trainees also evaluate scientific program and trainer efficiency on structured predefined criteria. For the matter of confidentiality, all evaluations and feedbacks are forwarded to NETSSAC. This feedback helps in making necessary changes in training modules and faculty selection.

\section{Gap-based Feedback :}

Gap-based feedback is obtained by personal communication (email). It is required to assess the translational effect of training into improved surgical performance and patient outcome.

\section{RESULTS :}

\section{Formulation of Structured Simulation- based Skills Training Program :}

Simulation in neurosurgery has made a significant step in education and skills training on an academic and translational platform (Fig. 2) (14).

The structured simulation neurosurgery skills training program consisted of Basic, Intermediate and Advanced Modules. The modules were graded based on their difficulty and fidelity. The Basic and Intermediate Modules are predominantly low fidelity task-based modules to acquire eye-hand coordination, instrument and tissue handling, dexterity and smooth flow of procedure. The Advanced Modules are predominantly high fidelity cadaveric procedure-based modules for training in surgical approaches using the basic and intermediate skills. These were provided to the trainees of our institute based on their year and level of training.

\section{Micro-Neurosurgery Skills Training Modules (Fig. 3) :}

These module starts with instructions regarding handling of microscope and micro-instruments, and the micro-suturing techniques. Basic and Intermediate Modules are practiced over silastic sheet (marked with squares of $1 \mathrm{x}$ $1 \mathrm{~cm}^{2}$ area) mounted on a fixation board. After making $1 \mathrm{~cm}$ straight incision on the silastic sheet, trainee practices tying interrupted knots with suture and magnification according to his level. In the Basic Module, 4-0 Silk, 5-0 Silk and 7-0 monofilament sutures are used at lower magnifications / magnification factor (MF) $(2.83 / 0.4,4.25 / 0.6$ and 7.08/1.0). In the Intermediate Module finer monofilament suture material like 90 and 10-0 Nylon are used at higher magnifications (11.33/1.6 and 17.71/2.5).

\section{Advanced Micro-suturing Skills Training Module:}

This module comprises of handson micro-suturing practice over high fidelity 'Live Animal Tissue Module' 
(LATM). The rat or guinea pig is anesthetized using intra-peritoneal phenobarbital. The sciatic nerve is exposed under lower magnification. The nerve is sectioned and anastomosis is performed with fine monofilament sutures (Nylon 10-0) under high magnification (11.33/1.6 and 17.71/2.5). Following successful nerve anastomosis, the trainees perform micro-vascular anastomosis of rat femoral artery under high magnification with 10-0 Nylon. Following exposure of the target artery, the clamps are applied on either sides of site of incision. The cut edges are stained with Methylene Blue for vessel demarcation. The blood clots at the edges are flushed with heparinized saline. Heel and toe approximation sutures are placed at the two ends; three to four interrupted sutures are placed on one side and the vessel is turned over and similar fine sutures are placed on the other side. The patency is checked by release of the clamps.

\section{High Speed Drill Skills Training Modules (Fig. 3) :}

Basic Module consists of naked eye drilling over freeze-dried sheep head and scapula (Cadaver Animal Tissue Module - CATM). In the Intermediate Module, trainee practices drilling under microscope on flat and curved bones (freeze dried sheep scapula and head) over an area marked with stencil (Neuro-DrillTrainer-Stencil Patent application number: 2874/DEL/2014). The "Stencil" marks a square with predefined areas for burr-hole placement and interconnecting drill path in set directions. Initial drilling is done with cutting match-head drill bit followed by diamond match-head drill bit to preserve the inner membrane (periosteum or dura). Following elevation of the flap/calvarium, it is split with fine tapered drill bit. The eggshell drilling using fine diamond match-head drill bit without breaching the inner membrane is also a part of this module.

The Advanced Module is a 'Cadaveric Neuro-anatomy Dissection Module' (CNADM) incorporating planning, techniques and tips for usage of high-speed drills in cadaveric microscopic skull base approaches e.g. anterior clinoidectomy, anterior and posterior petrosal approaches, far lateral approaches. (3D Microscope: Sony Inc., Japan and Carl Zeiss, Germany). The Advanced Modules consist of anatomical demonstration, pathological and radiological discussions regarding lesions for which the approach is used, surgical operative videos, 3D cadaveric demostrations and hands-on cadaveric dissection.

\section{Neuro-endoscopy Skills Training Modules (Fig. 3) :}

In the Basic Module, the trainee is familiarized with endoscope part assembly and eye-hand coordination practice. They practice on natural simulations like capsicum and papaya. Inner structures of capsicum and papaya simulate endonasal and ventricular anatomy respectively. Trainees practice biopsy, and pick and place in these 
modules to develop dexterity and eyehand coordination. It helps acclimatize to the changed anatomy (3-dimensional to 2dimensional visualization) and ergonomics.

The Intermediate Module involves practice on a box trainer called Neuro-Endo-Trainer. (Patent application number: $2875 / \mathrm{DEL} / 2014)$. It is a training box with 12 pegs on a rotatable base plate. There are 6 rubber rings around the pegs. Each session consists of picking and placing of the rings from the object area to the target area. The patterns for training are:

1) Pick and place the rings from object to target area in horizontal manner.

2) Pick and place the rings in diagonal manner, back to earlier arrangement.

The activity is recorded with endoscopic camera for evaluation. The trainees perform endoscopy practice with the base plate in three different positions namely, straight $\left(0^{\circ}\right)$, left tilt $\left(+30^{\circ}\right)$ and right tilt $\left(-30^{\circ}\right)$ providing a perceptual switch. Initial practice is performed with 0 degree scope followed by 30 and 45 degrees scopes.

The Advanced Module has 'Synthetic Simulation Module' (SSM) and 'Cadaveric Neuro-anatomy Dissection Module' (CNADM) to detail the intricacies of skull base and ventricular neuro-endoscopy techniques. Skull base neuro-endoscopy sub-modules include endoscopic anatomy of sella and skull base, and endoscopic endonasal approach to pituitary and extended skull base. The skull base cadaveric demostrations are done with 3D endoscope for better anatomic orientation (3D Neuroendoscope, Vision Sense Inc, USA). Ventricular neuro-endoscopy submodules comprise of endoscopic anatomy of ventricles, and its approaches e.g. Endoscopic Third Ventriculostomy (ETV) and endoscopic treatment of intraventricular cysts and lesions.

\section{Spine Instrumentation Module :}

Basic Spine Module familiarizes the trainee with spine anatomy and identification of landmarks and entry points for commonly practiced surgical approaches.

Intermediate and Advanced Spine Instrumentation Skills Training Modules: Training in these modules include detailed study of cervical, dorsal and lumbar spine instrumentation and hands-on practice on synthetic models (saw bones).

- Cervical spine: anterior cervical plate fixation, odontoid screw fixation, posterior occipito-cervical fixation and C1-C2 transarticular screw fixation.

- Dorsal and lumbar spine: pedicles screw fixation and anterior thoracolumbar fixation.

\section{Summative assessment :}

\section{Content Evaluation (Summative Assessment) :}

Till December 2013, 179 trainees attended 12 neurosurgery skills training workshops. Trainees consistently rate these workshops high (Fig. 4). 

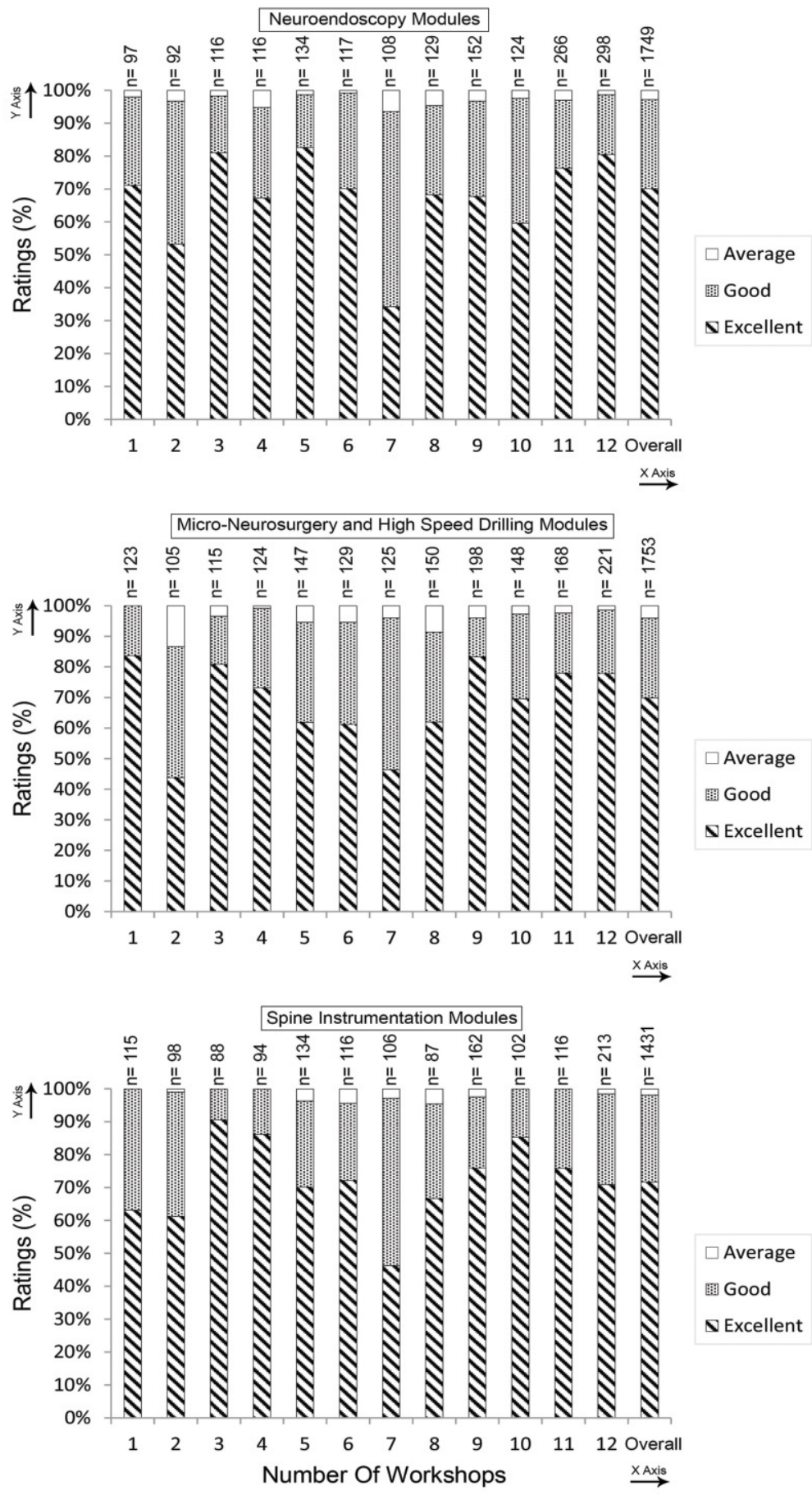

Fig. 4: Ratings of Neuroendoscopy, Micro-suturing, High Speed Drilling, and Spine Instrumentation Modules 


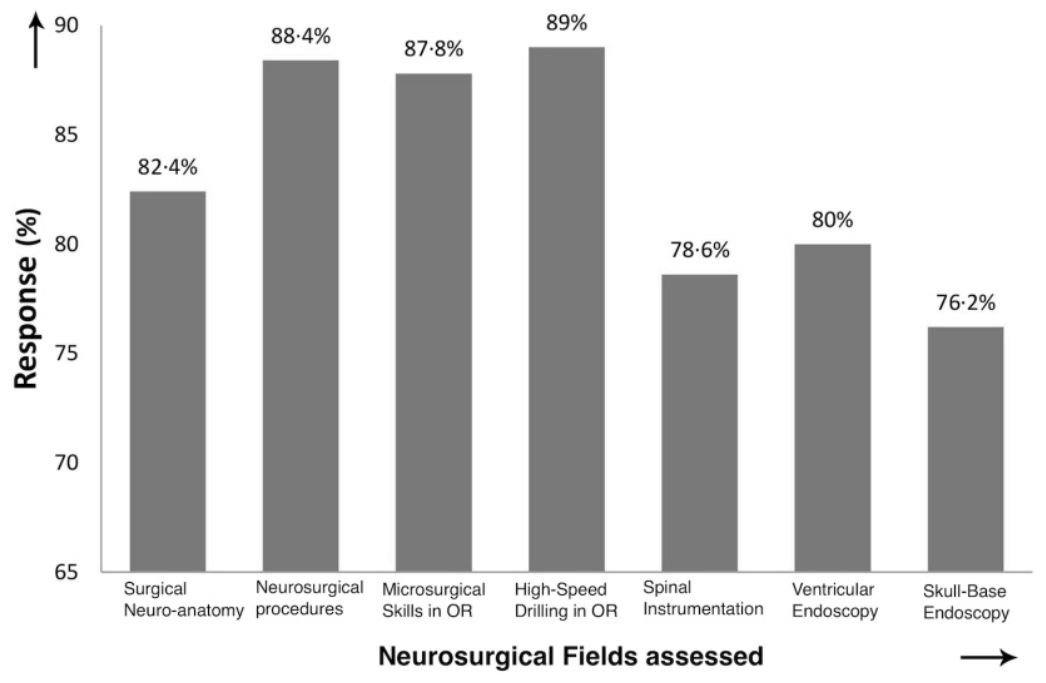

Fig. 5: Gap-based Evaluation

Faculty Evaluation (Summative Assessment):

Faculty evaluation is of prime importance to decide candidates with $\mathrm{CI}$ potential. For inter-faculty comparison, we have chosen only excellent markings. Only faculty with participation in $\geq 3$ workshops, were included in comparative analysis (Fig. 4).

\section{Gap-based Evaluation :}

179 workshop trainees were contacted with emails for long-term feedback. Among these, 22 emails could not be delivered. 34/157 (21.7\%) trainees responded back and the mean of component-based feedbacks is depicted in Fig. 5. Trainees were maximally benefitted in high-speed drilling followed by micro-neurosurgery. Most of the trainees were satisfied with content modules and teaching faculty, but $23.8 \%$ trainees were still not confident with skull-base endoscopy. This highlights the deficit of training in neuro-endoscopy in existing residency program, which needs a reform.

\section{Discussion :}

Skills training in a dynamic educational environment is an inevitable aspect in any field, especially when it involves nimbleness and dexterity. Achievement of surgical competence is a complex process that involves the attainment of knowledge, judgment, professionalism and surgical skills (20). In depth knowledge of the rules and legerdemains of any sport cannot increase the manoeuvrability of a naïveté, unless allowed to practically experiment with the respective equipment along with stringent training. For a neurosurgeon, it becomes furthermore imperative to manoeuvre the tactics of basic surgical skills to deal with 
the demanding situations encountered almost daily in neurosurgery OR. Iatrogenic injuries are the eighth leading cause of death in America and occur in approximately $4 \%$ of hospitalizations (1924). Council of State Neurosurgical Societies post-residency survey shows inadequate level of general neurosurgical training felt by $20 \%$ of board-certified neurosurgeons. This is later on reflected by large number of them (40\%) taking part in different fellowships after completing residency program (5).

\section{Surgical Skills Training Programs: Competency cum Period Based Training} :

Surgical subspecialties emphasizing minimally invasive procedures (like obstetrics and gynaecology, laparoscopic surgery) have foreseen the need of laboratory training for capacity building. Reznick et al (24) have discussed the utilization of available 'low and high fidelity' laboratory models for surgical training, depending upon the degree to which they replicate surgical substrate. Bench models are cheap, reusable and low fidelity; useful for teaching novices, the basic skills such as suturing, knot tying and instrument manipulation. Live animals and cadavers are high fidelity models allowing a trainee with advanced procedural knowledge to practice and refine entire surgical procedures. Spectrum of these devices stretches from simple homemade cardboard boxes to the most advanced 3D surgical simulator incorporating haptic interfaces and advanced graphics. From observations on the performance of expert musicians, chess players and athletes, it has been shown that the level of expertise thus attained is dependent on the time devoted to deliberate practice. 'Deliberate practice' involves focusing on a particular step, identified by an expert instructor, with an aim to improve trainees overall performance for a given task. Following the same logic, breaking down surgical procedures into modules designed for lab practice is also expected to benefit a trainee in better utilization of his time (24).

\section{Contemporary Training Programs in Neurosurgery:}

It can be argued that neurosurgical operations are complex and its replication in a laboratory may not always be feasible. With limiting volume of exposure and decreased time in OR, opportunities to learn are getting less. An effective strategy for acquisition of expertise in such a scenario is a time honoured deliberate competency based practice $(25,26)$.

Imparting basic neurosurgical skills and simulation of common surgical procedures, outside the OR answers the need for a non-threatening environment, closely mimicking surgical settings, where a trainee can practice at comfortable pace. Most of the existing simulation models are low fidelity with non-structured criteria for skills evaluation. Only a few of these skills training programs are replicable to neurosurgical scenario. SNS bootcamp course has a promising impact in development of neurosurgery skills 
training curriculum to be incorporated into routine residency program $(27,28)$.

\section{Neurosurgery Skills Training Curriculum (NSTC):}

Curriculum design involves multidisciplinary consultation and research paying due attention to the needs of residents, work hour restriction and societal needs. This integrates opinions of residents, health professionals, administration officials, governmental policies, educationalists and industrial designers (28). Modular curriculum emphasizes the use of bench models for training basic task-based skills (28), which can further augment trainees' experience with cadavers and live animals for procedural skills. "Three stage theory of motor skill acquisition" explains that minutiae's of procedural skills can be grasped only after mastery at basic surgical skills (28). A surgeon incompetent at this basic step cannot learn the advanced stages of the field. A standardized simulation program incorporates the benefits of aforementioned low and high-fidelity training systems (Fig. 5). It allows supervision, self-instruction and practice of basic and advanced surgical techniques. Trainee attending short-term skills training program gradually improves by self and expert assessment (formative assessment). The workshops focus on trained certified neurosurgeons to revise, update and evaluate procedural skills on high-fidelity simulation models (summative assessment).

\section{Skills Evaluation Criteria :}

Skills evaluation criteria have been a matter of debate since the advent of simulation systems. Most of these criteria have been developed for general surgical skills evaluation and none for neurosurgery skills (microscopic and endoscopic). For objective skills evaluation, we have followed objective assessment criteria with neurosurgical perspective, namely "NETS criteria" (Table 2).

\section{e-Learning Platform :}

We believe that there should be no time, place or monetary constraints for any learner of any class or creed that could limit their potential because of unavailability of learning material. eLearning platform provides learner's control over content, learning sequence, pace of learning and time, making it a "quick surf, find and extract" platform, allowing them to meet their individual learning objectives. Neurosurgeons can collaborate, discuss and contribute in the process of learning, and the educators become facilitators of the learning process rather than deliverers while students become participants rather than listeners (17).

\section{Skills Transferin OR :}

$80 \%$ of trials have suggested that there is significant improvement in NETS score in OR after simulation training (29, 30 ). Laboratory training methods may abbreviate only the initial part of the 
learning curve associated with acquisition of basic procedural skills (31). Nevertheless, the implementation of such methods will enable a trainee to be more efficient and productive with time. Gapbased evaluation indicates that workshop attendees feel more comfortable in OR after high-fidelity simulation training.

\section{Suggested guidelines:}

There is an earnest need for neurosurgery skills training curriculum reform in accordance with the existing educational and training demands. Good quality papers specifically on education written by neurosurgeons are sparse over the last 30 years (2). To fill gaps in education system, skills training curriculum should aim at:

- Supplementing existing system of Halstedian apprenticeship model of teaching.

- Shortening time required to learn basic skills of neurosurgery: acquisition of minimal level of competency.

- Training significant part of the learning curve outside OR, to enhance patient safety and to provide opportunity for focused practice.

- Encouragement of evaluation based improvement of skills acquisition.

- Open source, free access e-learning material, irrespective of geographical boundaries.

- Capacity Building: Encouragement of trained practicing neurosurgeons to play the role of faculty in future.

- Collaborative training by visiting consultants from various institutes.
- With the modular based studies, it is well evident that skills training cannot be imparted only with the help of workshops; rather should be as a part of the regular residency program. This will be in par with the technical advancements and provide sufficient time for skills acquisition. So, it becomes necessary to pay proper attention to incorporate such programs to maintain same level of skill and expertise among all neurosurgeons to protect and preserve quality neurosurgical education now and in future $(32,33)$.

\section{Conclusion :}

Technical evolution in surgery has created new skill sets and techniques that must be mastered by both practicing surgeons and trainees prior to clinical application. With modular training program, it is evident that skills training cannot be imparted only with help of workshops; rather should be part of regular residency program. This will be in par with technical advancements and provide sufficient time for skills acquisition.

We do not oppose time honoured years-in-place based training system but propose to substantiate it with competency-based training. Positive results of incorporation of skills training curriculum may be regarded as a value base for such programs in other branches of medical practice. This would help in achieving greater visibility in professionalism imperative for high-end 
branches like neurosurgery and proven competency at the end of training program.

\section{Acknowledgement :}

We give our sincere thanks to Prof. PN Tandon, Prof. AK Banerjee, Prof. VS Mehta, Prof. AK Mahapatra and Prof. BS Sharma for their untiring efforts and guidance in establishing this laboratory. We are grateful to our National Advisory Committee, teaching faculty and fellows Dr. Christoph Busert, Dr. Marcus Mehlitz, Prof. Ari Chako, Prof. Manas Panigrahi, Prof. Ravi M Rao, Prof. Shashank S Kale, Prof. Somana Sampath, Prof. Sunil K Gupta, Prof. Sanjay Behari, Prof. Rajkumar, Prof. Manoj K Tewari, Prof. Dilip Panikar, Prof. Daljit Singh, Prof. Sanjiv Sinha, Prof. Manmohan Singh, Prof. Deepak Gupta, Prof. Renu Dhingra, Prof. D N Bhardwaj, Prof. Sanjiva Prasad, Prof. Subhashis Banerjee, Prof. Prem Kalra, Prof. Subodh Kumar, Prof. Kolin Paul, Prof. Sneh Anand, Prof. R M Pandey, Dr. Rama Chandra Deo and Dr. Natesan Damodaran for their selfless support. We would like to acknowledge the efforts of technical and application specialists from Neurosurgery Skills Training Facility, Neurosurgery Education and Training School, All India Institute of Medical Sciences, New Delhi, India. We thank Miss Payal Jotwani, Miss Britty Baby, Mr. Vinkle Srivastava, Mr. Ramandeep Singh, Mr. Subhas Bora, Mr. Ajab Singh, Mr. Ram Niwas, Mr. Shashi Shekhar, Mr. Trivendra Yadav, Mr. Gaurav Bharadwaj, Mr. Suresh Kothari, Mr. Vikram Singh, Mr. Satish Kumar for their untiring valuable support.

This manuscript is the result of research projects funded by extramural grants from Indian Council of Medical Research (ICMR), Ministry of Health and Family Welfare, Govt. of India; Dept. of Biotechnology (DBT), Ministry of Science and Technology, Govt. of India and BMBF, Germany- Indo-German Collaboration; Dept. of Health Research (DHR), Indian Council of Medical Research (ICMR), Ministry of Health and Family Welfare, Govt. of India; Dept. of Science and Technology (DST), Ministry of Science and Technology, Govt. of India. Authors declare 'no beneficiary role' of any funding agency or authors.

\section{REFERENCES :}

1. Barnes RW, Lang NP, Whiteside MF (1989). Halstedian technique revisited. Innovations in teaching surgical skills. Ann Surg 210:118121.

2. Long DM (2000). Competencybased Residency Training: The Next Advance in Graduate Medical Education. Acad Med 75:1178-1183.

3. Anastakis DJ, Regehr G, Reznick RK, et al. (1999). Assessment of technical skills transfer from the bench training model to the human model. Am J Surg 177:167-170.

4. ACGME, Accreditation Council for Graduate Medical Education. Program and Institutional 
Accreditation, Surgical Specialties, Neurological Surgery (Accessed Dec 29, 2013 at http://www.acgme.org/ acgmeweb/tabid/135/ProgramandIn stitutionalAccreditation/SurgicalSpe cialties/NeurologicalSurgery.aspx).

5. Mazoola CA, Lobel DA, Krishnamurthy S, Bloomgarden GA, Benzil DL (2010). Efficacy of Neurosurgery Resident Education in the New Millennium: The 2008 Council of State Neurosurgical Societies Post-Residency Survey Results. Neurosurgery 67:225-233.

6. Reznick RK (1993). Teaching and testing technical skills. Am J Surg 165:358-361.

7. Reznick RK, Regehr G, MacRae H, et al. (1997). Testing technical skill via an innovative "bench station" examination. Am J Surg 173: 226 -230 .

8. Halm EA, Lee C, Chassin MR (2002). Is volume related to outcome in health care? A systematic review and methodologic critique of the literature. Ann Intern Med 137:511-520.

9. Patel NV, Robbins JM, Shanley CJ (2009). Low fidelity exercises for basic surgical skills training and assessment. Am J Surg 197:119-125.

10. Yasargil MG (1999). A legacy of microneurosurgery: memoirs, lessons and axioms. Neurosurgery 45:1025-1092.
11. Yasargil MG (2010). Personal considerations on the history of microneurosurgery. $J$ Neurosurg 112:1163-1175.

12. Tripathi M, Deo RC, Suri A, et al. (2015). Kawase's Triangle versus Modified Dolenc Kawase Rhomboid Approach for Middle Cranial Fossa Lesions with Variable Anteroposterior Extension. $J$ Neurosurg 3:1-9.

13. Suri A, Tripathi M, Deo RC (2014). Anterolateral Trans-Cavernous Extradural Petrosectomy Approach: 3-D Demonstration in Cadavers. Neurosurgery Suppl 4, 656.

14. Suri A, Roy TS, Lalwani S, et al. (2014). Practical Guidelines for Setting Up Neurosurgery Skills Training Cadaver Laboratory in India. Neurol India 32(3): 1-8.

15. Suri A, Bettag M, Tripathi M, et al. (2014). Simulation in Neurosurgery in India- NETS. CNS Quarterly 3:2326.

16. Suri A, Tripathi M, Baby B, Banerji S (2013). Beyond the Lenses: Development of Hands-on and Virtual Neuroendoscopy Skills Training. Venkataramanaa NK, Suri A, Deopujari CE, eds. Clinical Neuroendoscopy. Current Status- by Neuroendoscopy Study Group of India, New Delhi: Thieme Publishers. 139-149. 
17. Jotwani P, Srivastav V, Tripathi M, et al. (2014). Free-access Open-source e-Learning in Comprehensive Neurosurgery Skills Training. Neurol India 62(4): 352-361.

18. Tripathi M, Deo RC, Damodaran N, et al. (2015). Quantitative Analysis of Variable Extent of Anterior Clinoidectomy With Intradural and Extradural Approaches: 3D Analysis and Cadaver Dissection. Neurosurgery 11(3):147-161.

19. Selden NR, Origitano TC, Burchiel $\mathrm{KJ}$, et al. (2012). A national fundamentals curriculum for neurosurgery PGY1 residents: the 2010 Society of Neurological Surgeons boot camp courses. Neurosurgery 70:971-981.

20. Satava RM, Gallagher AG, Pellegrini CA (2003). Surgical competence and surgical proficiency: definitions, taxonomy and metrics. J Am Coll Surg 196(6):933-937.

21. Kohn LT, Corrigan JM, Donaldson MS eds. (2000). To Err is Human: Building a Safer Health System, Washington, DC: National Academy Press; 2000.

22. Gawande AA, Thomas EJ, Zinner MJ (1999). The incidence and nature of surgical adverse events in Colorado and Utah in 1992. Surgery 126(1):6675.
23. Blum BL, Sigllior VG (1986). An expert system for designing information systems. John Hopkins APL Technical Digest 7:23-31.

24. Reznick RK, MacRae H (2006). Teaching surgical skills--changes in the wind. NEJM355:2664-2669.

25. Ericsson KA ed. (1996). The road to excellence: the acquisition of expert performance in the arts and sciences, sports and games. Mahwah, NJ, Lawrence Erlbaum Associates.

26. Long DM (2004). Competencybased training in Neurosurgery: The next revolution in Medical Education. Surg Neurol 61:5-25.

27. Satava RM, Cuschieri A, Hamdorf J (2003). Metrics for objective assessment. Surg Endosc 17(2):220-226.

28. Fitts PM, Posner MI (1967). Human Performance. Belmont, CA: Brooks/Cole, 162 p.

29. Buckley CE, Kavanagh DO, Traynor O, Neary PC (2014). Is the skillset obtained in surgical simulation trasferable to the operation theatre. Am J Surg 207:146-157.

30. Grober ED, Hamstra SJ, Wanzel KR, et al. (2004). Laboratory based training in urologic microsurgery with bench model simulators: a randomized controlled trial evaluating the durability of technical skill.JUrol 172:378-381. 
31. Sedlack RE, Kolars JC (2004). 33. Anastakis DJ, Regehr G, Reznick Computer simulator training enhances the competency of gastroenterology fellows at colonoscopy: results of a pilot study. Am J Gastroenterol 99:33-37.

32. Lawton MT, Narvid J, QuinonesHinojosa A (2007). Predictors of neurosurgical career choice among residents and residency applicants. Neurosurgery 60(5):934-939. RK, et al. (1999). Assessment of technical skills transfer from the bench training model to the human model. Am J Surg 177:167-170. 